\title{
Relationship between respiratory symptoms and medical treatment in exacerbations of COPD
}

\author{
P. Calverley*, R. Pauwels ${ }^{*}, \dagger$, C-G. Löfdahl`" K. Svensson ${ }^{+}$, T. Higenbottam ${ }^{\S}$, \\ L-G. Carlsson ${ }^{+}$and E. Ståhi ${ }^{\dagger+}+$
}

ABSTRACT: Exacerbations of chronic obstructive pulmonary disease (COPD) can be defined symptomatically or by healthcare contacts, yet the relationship between these events is unknown. Data were collected during a 1-yr study of the budesonide/formoterol combination in COPD patients, where exacerbations, defined by increases in treatment, were compared with daily records of respiratory symptoms, rescue medication use and peak expiratory flow (PEF).

The relationship between changes in these variables and the medical event was examined using different modelling approaches. Data from the first exacerbation treated with oral corticosteroids and/or antibiotics and/or hospitalisation (event based) were available in 468 patients.

Patients exacerbating were significantly more breathless and more likely to report cough than healthy patients, but did not differ in baseline spirometry. Exacerbations defined by changes in individual symptoms were only weakly related to event-based exacerbations; however, defined with $63 \%$ of such events being predicted from symptom changes. Changes in rescue medication use or PEF were poor predictors of event-based exacerbations. The mean peak change in symptoms was closely related to the onset of therapy.

In conclusion, event-based exacerbations are a valid way of identifying acute symptom change in a chronic obstructive pulmonary disease population. However, daily symptom monitoring is too variable using the current diary cards to make individual management decisions.

KEYWORDS: Chronic obstructive pulmonary disease, concurrence, events, exacerbations, symptoms

hronic obstructive pulmonary disease (COPD) is a major cause of morbidity and mortality, and is the only leading cause of death that is increasing in prevalence [1]. Acute exacerbations of COPD contribute significantly to the individual's disease burden, and an increased frequency of these episodes may hasten disease progression and possibly accelerate rate of decline in lung function [2-4]. Acute exacerbations are also associated with a poor prognosis, with hospital mortality rate ranging from $3-10 \%$ in severe patients $[5,6]$. If intensive care unit admission is required, the rate is substantially higher, with $>30 \%$ mortality in patients $>65$ yrs of age [7].

To understand the causes and evaluate treatment that could change the severity or frequency of exacerbations, a robust and reproducible definition of what constitutes an exacerbation is required. Several approaches to defining an exacerbation have been proposed and each has its disadvantages [8]. The most commonly used, and the one recognised most easily by patients themselves, involves a sustained increase beyond the normal variability in respiratory symptoms (dyspnoea, cough, sputum volume and sputum purulence) [9]. Other symptom-based definitions have been developed, but none have been validated in terms of their reliability and responsiveness [2, 10-14]. An alternative approach to definition identifies episodes where symptoms increase and there is a medical "event", e.g. a change of therapy (antibiotics or oral corticosteroids) or management (admission to hospital) [15-19]. This practical definition avoids the subjectivity of a change in symptoms and usually requires the involvement of a medical professional in the diagnostic process.

Although most clinicians assume that these approaches are broadly comparable, there has

\section{AFFILIATIONS}

*Dept of Medicine, University Hospital Aintree, Liverpool, and ${ }^{\S}$ AstraZeneca, Charnwood, UK. \#Dept of Respiratory Diseases, Ghent University Hospital, Ghent, Belgium. "Dept of Respiratory Medicine and Allergology, University Hospital, and ${ }^{+}$AstraZeneca, Lund, Sweden.

CORRESPONDENCE

P. Calverley

The University Hospital Aintree Liverpool Longmoor Lane L9 7AL UK Fax: 441515295888 E-mail: pmacal@liverpool.ac.uk

Received:

December 152004

Accepted after revision:

May 092005 
not been any direct comparison of events defined using these different approaches. The hypothesis presented here is that there would be a consistent increase in one or more key symptoms in the period around the time of any medical consultation defined as being an exacerbation. This would allow identification of discrete episodes that could form the basis of an automated exacerbation-detection algorithm. These concepts were tested by retrospectively analysing data collected as part of a large clinical trial, where event-based exacerbations were prospectively defined, and in which patients had recorded daily symptom and peak expiratory flow (PEF) data using a diary card approach validated in bronchial asthma [20]. The primary analysis of this clinical trial data has already been published [18].

\section{METHODS}

\section{Study design and patients}

The present study utilised data from a 12-month, randomised, placebo-controlled, parallel-group study of 796 patients with available data (patients experiencing at least one exacerbation) in 11 countries (mean age $64 \mathrm{yrs}$, mean forced expiratory volume in one second (FEV1) $0.99 \mathrm{~L}, 36 \%$ predicted). Subjects were randomly assigned to take two inhalations b.i.d. of the following: $9 \mu \mathrm{g}$ formoterol; $400 \mu \mathrm{g}$ budesonide; budesonide/ formoterol combination in a dose of $320 / 9 \mu \mathrm{g}$ respectively per inhalation; or placebo [18]. The study included one enrollment visit, one visit after a 2 -week run-in period (visit two) and six subsequent visits during the treatment period.

Diary cards were distributed at visits one to seven and collected at visits two to eight. The diaries were carefully reviewed by the investigator together with the patient. Comments judged by the investigator to indicate an adverse event were noted in the appropriate section of the clinical record form.

The diary cards included the following daily recordings: 1) PEF morning and evening; 2) whether rescue medication was taken during the $6 \mathrm{~h}$ prior to PEF measurement; 3) daytime COPD symptom scores; 4) night-time awakenings due to COPD symptoms; 5) intake of study medication morning and evening; 6) intake of rescue medication and cough medicines (anti-tussives) morning and evening; and 7) intake of oral steroids, antibiotics, healthcare contacts and sick-leave related to COPD symptoms.

A mini-Wright peak flow meter (Clement Clark, Harlow, UK) and a diary card were dispensed at visit one. The patients were carefully instructed in the use of the peak flow meter. All measurements were to be made while standing. Rescue medication (bricanyl turbuhaler $0.5 \mathrm{mg} \cdot \mathrm{dose}^{-1}$ ) was not to be taken for $6 \mathrm{~h}$ prior to PEF measurement. The patients were instructed to perform three manoeuvres twice daily (morning and evening), the highest value on each occasion being recorded in the diary. The morning measurement was made immediately upon rising before taking the study medication. Similarly, the evening measurement was made before going to bed and before the evening dose of study medication.

\section{Definitions}

Event-based exacerbations

Event-based exacerbations were defined as use of oral corticosteroids and/or antibiotics and/or hospitalisation for a worsening in the patient's respiratory symptoms at the discretion of their usual physician. These events were captured as severe exacerbations in the original study [18].

\section{Symptom-based exacerbations}

Symptom-based exacerbations were defined retrospectively in a variety of ways (see below) using data recorded daily in diary cards. Four symptoms (shortness of breath, cough, chest tightness and night-time awakenings) were each assessed on a scale of $0-4$. The specific questions asked are listed in table 1. In addition, patients recorded daily use of short-acting $\beta_{2^{-}}$ agonist (rescue medication) and morning and evening PEF values. Diary cards were collected at each visit. Only diary card data related to the first event-based exacerbation during the 12-month follow-up are presented in the present study.

The day an event-based exacerbation was deemed to have occurred (i.e. day 0) was defined as the day on which hospital admission occurred or drug therapy was initiated, as identified on the diary card and/or a specific supplementary medicine record kept by the patient during the study and reviewed at the regular review visits. The number of symptom-based exacerbations occurring within 7 days of an event-based exacerbation was determined. Where overlap was seen, this was classified as "concurrence" and considered to be the same event. The maximum level of concurrence was, therefore, $100 \%$.

\section{Descriptive analysis}

The event-based exacerbation defined in the clinical study was used as the "gold standard". The relationship between the change in symptoms, increased rescue medication use and per cent predicted morning and evening PEF were compared with the first event-based exacerbation that occurred. The definitions used for change in symptoms are described below. Table 1 shows the percentage of days during the run-in phase where the indicated score was recorded. For each, the average score for each patient during run-in was calculated and used as a variable.

This was an exploratory analysis in which statistical assessment of differences between groups was not appropriate, since there was no a priori hypothesis to test between the different classification systems.

\section{Proposed classification systems}

Simple symptom, rescue medication and PEF algorithm

Table 2 lists the analyses performed using a simple algorithm based on symptoms, rescue medication use and change in morning PEF. Further exploration by varying the time window for the exacerbation (3,5 and 7 consecutive days, respectively) and time lag (28, 14 and 7 days before an event-based exacerbation, respectively) was also investigated.

\section{Combined symptom scores}

The various combined symptom scores explored in these analyses are also described in table 2. An arbitrary scale was developed for use in clarifying external rules that would allow definition of an exacerbation objectively or by automated means.

Subdivision of patients with event-based exacerbations

In order to examine the relationship between event- and symptom-based exacerbations, a number of exploratory 
TABLE 1 Baseline age and forced vital capacity in one second (FEV1) \% predicted normal, and symptoms during run-in

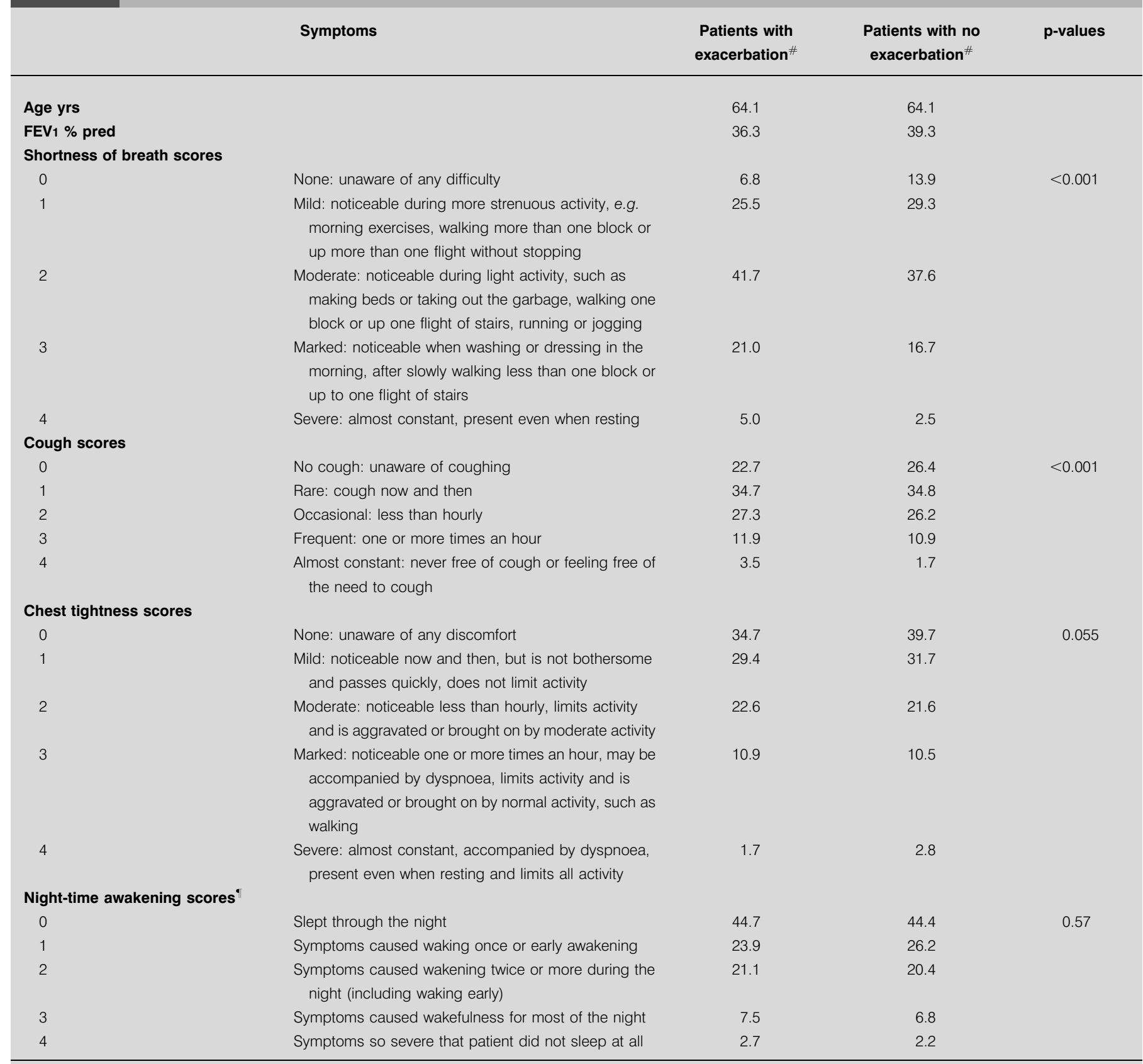

Data presented as \% unless otherwise stated. \#: per cent of days during the run-in period in which the indicated score was recorded for patients with and without eventbased exacerbations; $"$ : due to respiratory symptoms.

approaches were applied. Patients with event-based exacerbations were subdivided into different groups according to the following. 1) Three groups were subdivided according to the Global Initiative for chronic Obstructive Lung Disease (GOLD) definitions of severity: moderate stage II, severe stage III and very severe stage IV. 2) Three groups were subdivided on the basis of treatment approach, i.e. those receiving antibiotics, oral corticosteroids or hospitalisation. These groups included all patients receiving each approach and, therefore, there was some overlap between the groups.
Occurrence of symptoms, rescue medication and PEF in exacerbation-free intervals

The median change in symptoms, rescue medication and morning PEF from baseline to 2 days before an event-defined exacerbation (day 2) was calculated for the exacerbating (event-based) patients. This was compared on a daily basis for all patients to determine what proportion of patients exceeded the median values for each variable. The intention was to determine whether patients with an event-defined exacerbation also exhibited a change in symptoms, rescue 


\section{TABLE 2 Symptom algorithms}

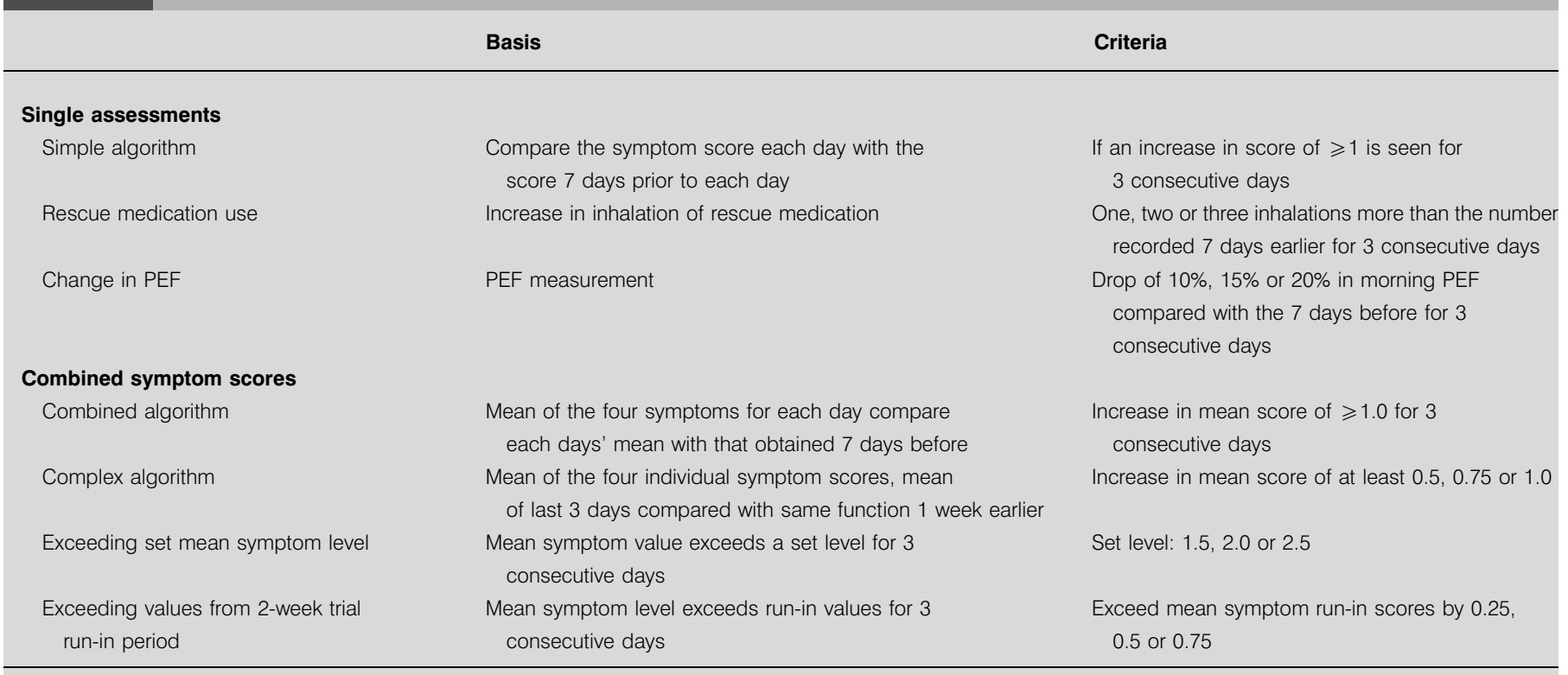

PEF: Peak expiratory flow.

medication use or morning PEF in the days prior to an eventbased exacerbation, thereby identifying any variable that was potentially predictive for an event-based exacerbation.

\section{RESULTS}

Of the 796 patients randomised to receive treatment, 468 patients experienced at least one event-based exacerbation, as defined by episodes requiring antibiotics and/or corticosteroids and/or hospital admission (fig. 1). All patients were classified in GOLD stages II-IV. The mean age of these patients was 64.1 yrs and the mean FEV1 \% pred was 36.3. The mean

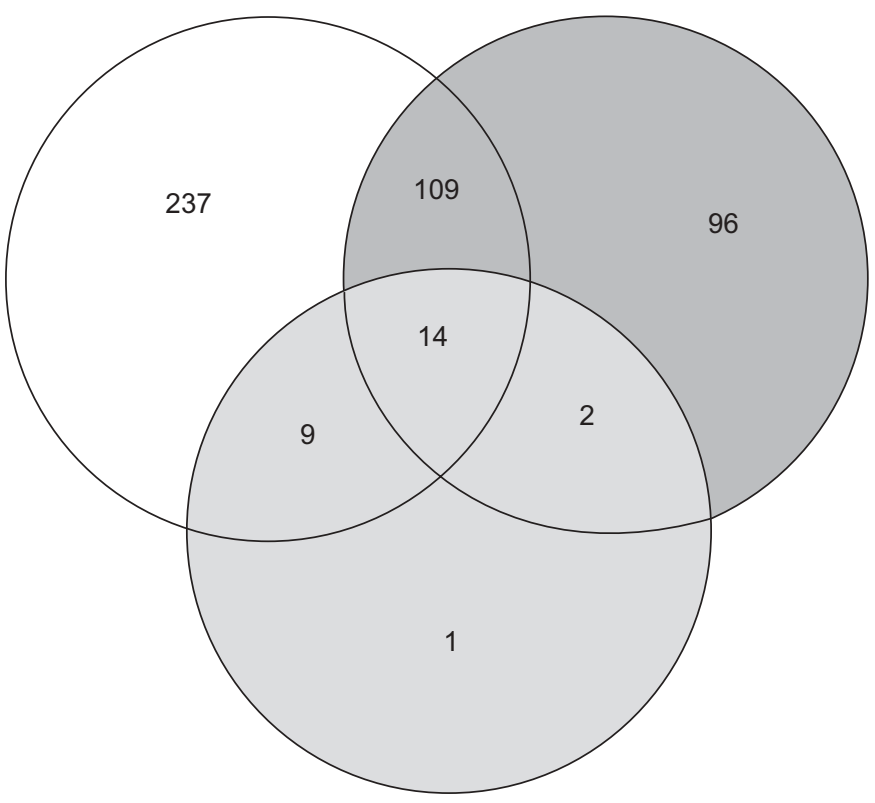

FIGURE 1. Event-based exacerbations. $\bigcirc$ : Antibiotics $n=369$; 0 : oral steroids $n=219 ; \quad$ : hospitalisation $n=25$. values of symptom scores (minimum 0; maximum 4) at baseline for these patients were as follows: 1) shortness of breath 1.9 ; 2) cough $1.4 ; 3$ ) chest tightness 1.2 ; and 4) night-time awakenings 1.0. The remaining 328 patients had a mean age of $64.1 \mathrm{yrs}$ and a mean FEV1 \% pred of 39.3. The mean symptom scores at baseline were somewhat lower: 1.6, 1.0, 1.3 and 1.0 for the four symptoms, respectively. Table 1 shows the age, FEV1 $\%$ pred and symptoms scores separated into two groups, one experiencing at least one event-based exacerbation and the other with no event-based exacerbation during the study period. There was a statistically significant difference in the symptoms, shortness of breath and cough between the groups (both $\mathrm{p}<0.001$ ).

Diary cards were well completed. The available number of records (days with data) averaged $87.8 \%$ during the study period (4 weeks after the day of exacerbation).

\section{Population changes}

The four individual symptom scores in the days preceding and following the first event-based exacerbation are shown in figure 2. The mean scores for the 468 patients clearly show a similar pattern across all symptoms, increasing steadily in the 2 weeks prior to an exacerbation and returning to baseline values $\sim 2$ weeks later. This pattern was seen irrespective of the medication used to treat the exacerbation, with a similar absolute change in symptom score for episodes treated with antibiotics alone or with corticosteroids.

Rescue medication use in the days pre- and post-exacerbation is shown in figure 3. Again, a change was noticed beginning $\sim 2$ weeks before an exacerbation, with increasing number of inhalations, and then a slow return to baseline values.

Morning and evening PEF, expressed as a per cent of the predicted values, in the days pre- and post-exacerbation are shown in figure 4 . As with the symptom scores, a clear change 


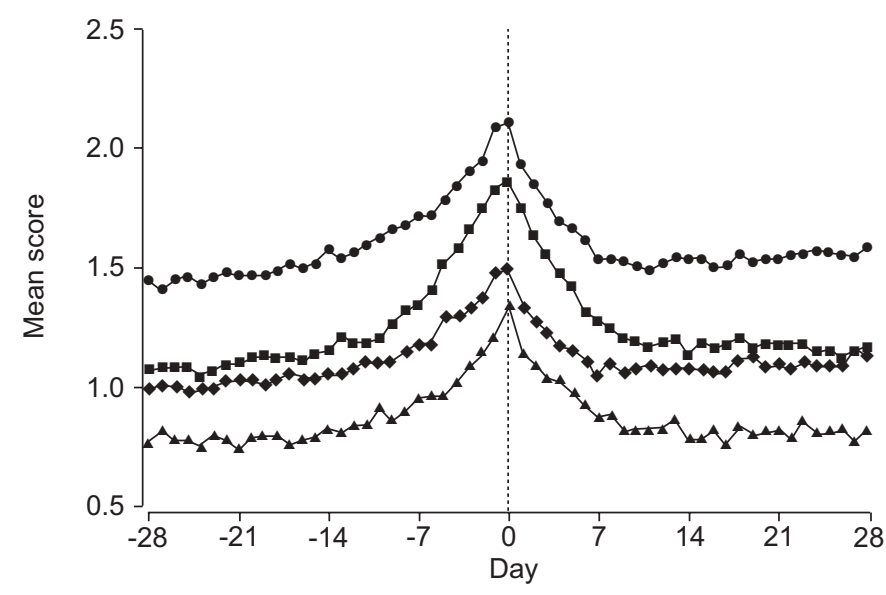

FIGURE 2. Mean values of symptom scores around the first protocol-defined exacerbation. $\bullet$ : shortness of breath; $\mathbf{\square}$ : cough; $\bullet$ : chest tightness; $\mathbf{\Lambda}$ : night-time awakening; - - -: day 0 , first day of exacerbations.

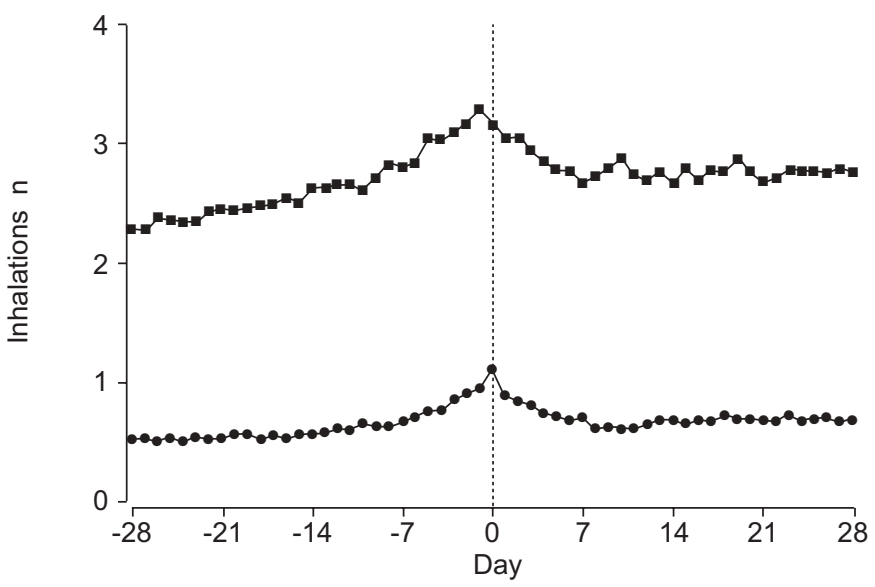

FIGURE 3. Mean values of intake of rescue medication.

rescue medication (day); - : rescue medication (night); - - -: day 0 , first day of exacerbations.

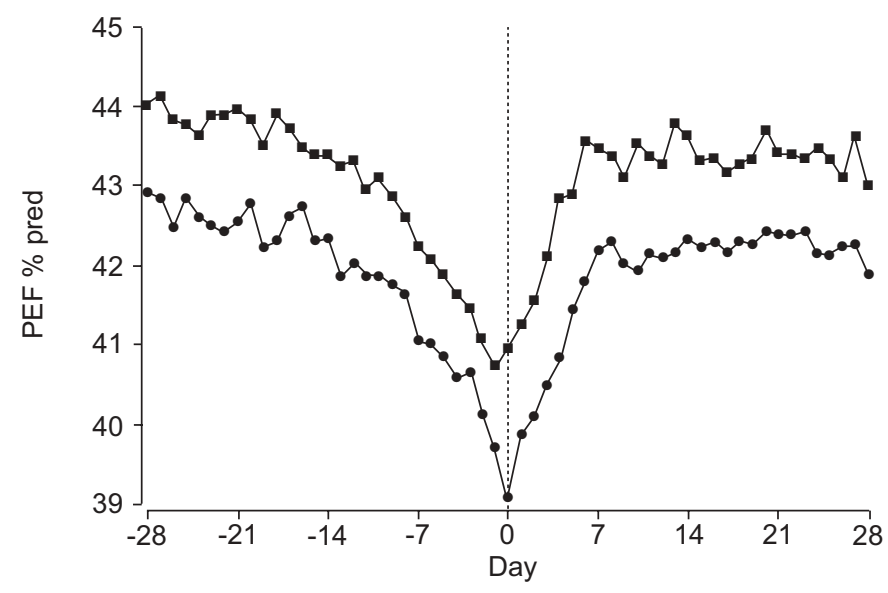

FIGURE 4. Morning peak expiratory flow (PEF) around the first exacerbation. - : PEF (evening); - PEF (morning); - - -: day 0, first day of exacerbation. in PEF is seen during the exacerbation, with PEF falling steadily (decreases in morning PEF of $9.0 \%$ and evening PEF of $7.7 \%$ being recorded) in the $2-3$ weeks before and returning to baseline values after $\sim 1$ week.

\section{Individual changes: simple algorithm, rescue medication and PEF}

Simple symptom-based exacerbation calculations

The results of the analyses to identify concurrence between changes in each of the four individual symptoms and eventdefined exacerbations are shown in table 3. For breathlessness, 660 out of 796 patients experienced a symptom-based exacerbation, as defined by the simple criteria, and 411 of these 660 patients also experienced an event-based exacerbation. However, only 206 of these 411 exacerbated within 7 days before and after the symptom-based exacerbation occurred, meaning that $44 \%$ of the event-based exacerbations were also captured by a change in breathlessness. Assessment of the other three symptoms showed a similar range of concurrence, with the change in cough symptoms occurring in $51.7 \%$ of the event-based exacerbations. For all symptoms, varying the time window to 5 and 7 days, or time lag from baseline to 14 and 28 days, had no notable influence on the results.

\section{Increased use of rescue medication}

The lowest condition (an increase of one inhalation for 3 consecutive days) was recorded by almost all patients at some time-point during the study (table 3). Approximately half of these were within 7 days of an event-based exacerbation. Restricting the criteria to two or three inhalations resulted in fewer symptom-based exacerbations, but also in a considerably lower percentage of concurrence.

\section{Changes in morning PEF}

Assessment of change in morning PEF \% pred was only weakly correlated with event-based exacerbations, with even

\section{TABLE 3 Results of analysis of single assessments}

\begin{tabular}{|c|c|}
\hline $\begin{array}{l}\text { Patients with } \\
\text { symptom-based } \\
\text { exacerbations }\end{array}$ & $\begin{array}{l}\text { Patients with } \\
\text { event-based } \\
\text { exacerbations }\end{array}$ \\
\hline
\end{tabular}

\begin{tabular}{llll}
\hline $\begin{array}{l}\text { Individual symptoms } \\
\text { Breathlessness }\end{array}$ & 660 & & \\
Chest tightness & 608 & 382 & $182(44.0)$ \\
Cough & 649 & 416 & $242(51.7)$ \\
Night-time awakening & 543 & 353 & $149(31.8)$ \\
Any symptom & 737 & 451 & $330(70.5)$ \\
Increased inhalations & & & \\
of rescue medication & & & \\
1 & 672 & 314 & $130(27.8)$ \\
2 & 469 & 183 & $65(13.9)$ \\
3 & 246 & & \\
Fall in morning PEF \% & & 162 & $40(8.6)$ \\
20 & 235 & 241 & $63(13.5)$ \\
15 & 352 & 373 & $128(27.4)$ \\
10 & 573 & & \\
\hline
\end{tabular}

Data presented as $n$ or $n(\%)$. PEF: peak expiratory flow. 
the smallest change $(10 \%)$ resulting in only $27.4 \%$ concurrence (table 3).

\section{Individual changes: combined symptom scores}

Combined algorithm

An arbitrary scale was developed for use in clarifying external rules which would allow definition of an exacerbation objectively or by automated means. The degree of concurrence achieved with this score is shown in table 4 , for both a 0.5 and a 0.75 change in combined symptom score (as defined in table 2). A large number of patients met the criteria defining a change in symptom score of $\geqslant 0.5$, but only 224 of these occurred in the time frame considered to be the same event as those described as event-based exacerbations. Increasing the condition to a change in symptom score of 0.75 selected fewer patients, but markedly reduced the degree of concurrence.

\section{Complex symptom-based definition}

This represents a moving average for 3 days compared with the average 7 days earlier, the objective being to minimise individual variation (as defined in table 2). A symptom-based criteria of an increase in mean symptom score of 0.5 resulted in almost $60 \%$ concurrence (table 4 ). Changing the criteria to an increase of 0.75 or 1.0 resulted in fewer symptom-based exacerbations and also a lower rate of concurrence.

\section{Symptom mean exceeding a set value}

Symptom-based events, defined as a mean symptom value exceeding a 1.5, 2.0 or 2.5 increase for 3 consecutive days, showed a relatively high degree of concurrence at the lower levels (table 4). A symptom-based exacerbation, defined as an increase of 1.5 for 3 days, was seen in almost all patients at

TABLE 4 Results of analysis of combined symptoms scores

$\begin{array}{cc}\text { Patients with } & \text { Patients with Concurrence } \\ \text { symptom-based } & \begin{array}{c}\text { event-based } \\ \text { exacerbations }\end{array} \\ \text { exacerbations }\end{array}$

\begin{tabular}{|c|c|c|c|}
\hline \multicolumn{4}{|c|}{$\begin{array}{l}\text { Increase in combined } \\
\text { symptom score of }\end{array}$} \\
\hline$\geqslant 0.50$ & 639 & 408 & $224(47.9)$ \\
\hline$\geqslant 0.75$ & 486 & 334 & 154 (32.9) \\
\hline \multicolumn{4}{|c|}{ symptom score of } \\
\hline$\geqslant 0.50$ & 676 & 427 & 279 (59.6) \\
\hline$\geqslant 0.75$ & 539 & 363 & $197(42.1)$ \\
\hline$\geqslant 1.0$ & 387 & 277 & $141(30.1)$ \\
\hline \multicolumn{4}{|l|}{ Level } \\
\hline 2.5 & 241 & 175 & 105 \\
\hline 2.0 & 399 & 283 & $190(40.6)$ \\
\hline 1.5 & 557 & 366 & 296 (63.3) \\
\hline \multicolumn{4}{|c|}{$\begin{array}{l}\text { Increase over run-in } \\
\text { values }\end{array}$} \\
\hline 0.75 & 319 & 232 & $138(29.5)$ \\
\hline 0.50 & 422 & 291 & $190(40.1)$ \\
\hline 0.25 & 536 & 348 & 247 (52.8) \\
\hline
\end{tabular}

Data presented as $\mathrm{n}$ or $\mathrm{n}(\%)$ some point, $63.3 \%$ correlating with an event-based exacerbation. Similar results were seen when symptom-based exacerbations were defined as an increase over the run-in period (table 4).

\section{Effect of COPD severity and therapeutic intervention}

Patients with an event-based exacerbation were classified into groups according to the GOLD definitions of severity (very severe stage IV: $n=158$; severe stage III: $n=246$; and moderate stage II: $n=64$ ) and the pattern of symptoms around the first event-based exacerbation assessed. While the symptom mean was seen to increase markedly in the 7-14 days preceding an event-based exacerbation and decline gradually with resolution, no difference in symptom curve was seen between the three severity groups. Assessment of individual symptoms showed a similar pattern, with only breathlessness separating into three distinct peaks at the point of an event-based exacerbation, with the very severe stage IV patients having the highest degree of breathlessness and the moderate stage II patients the lowest.

There was no significant difference in mean symptom scores if the patients were divided according to treatment (formoterol, budesonide, budesonide/formoterol combination or placebo).

\section{Occurrence of symptoms, rescue medication and PEF in exacerbation-free intervals}

As shown in figure 5, an increase in symptoms 2 days prior to an event-defined exacerbation was not seen to be predictive, as a similar proportion of patients had increased levels without resulting in an exacerbation. The same was evident for rescue medication use and PEF levels.

\section{DISCUSSION}

Although few clinicians have difficulty in recognising a patient with an exacerbation of COPD, agreeing on a comprehensive

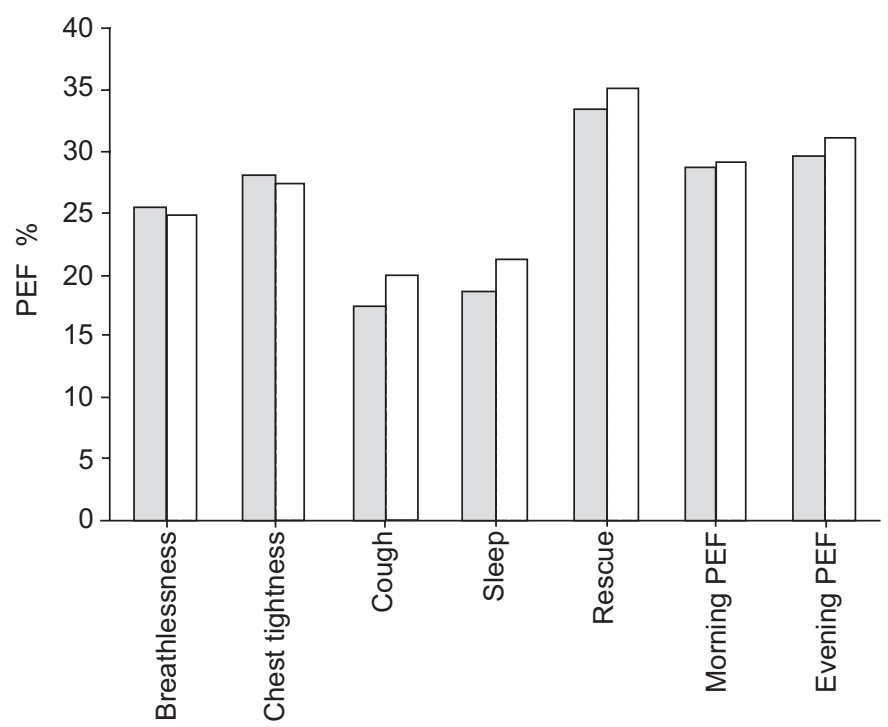

FIGURE 5. Mean percentage of days where symptoms, rescue medication and peak expiratory flow (PEF) exceed the median value for patients with eventbased exacerbations 2 days before their first exacerbation. $\square$ : no event-based exacerbation; $\square$ : event-based exacerbation. 
definition has been surprisingly difficult and is limited by the lack of studies where different approaches to defining an exacerbation have been compared. The present data, relating event-based episodes to changes in symptom intensity, are the first where such a comparison has been possible. Although, on average, symptom intensity peaked around the time therapy was initiated and declined thereafter. Individual symptombased episodes showed only limited agreement with episodes when the patient sought medical help. Combining the selected symptoms worsened rather than improved the degree of agreement between definitions.

There may be several reasons for this surprising finding. The patients might not have completed their diary cards around the time of an exacerbation (or have reported only one symptom of note). This was not the case as judged by the surprisingly good data completion in the weeks before and after event-based episodes. Retrospective completion of data cannot be excluded in some cases, but given the large number of subjects in different centres it would be surprising if this systematically biased the results.

The population studied was relatively severe, with an eventbased exacerbation rate of $1.8 \cdot \mathrm{yr}^{-1}$ of those randomised to placebo and $1.4 \cdot \mathrm{yr}^{-1}$ in those receiving the budesonide/ formoterol combination, in keeping with this severity of disease [21]. All symptoms showed, on average, similar changes around the time of the event-based episodes and rose to a similar degree. An increase in the use of rescue therapy paralleled these changes. The fall in PEF was $4.3 \%$ of predicted normal over the course of the event-based episodes, and was very similar to that seen when other symptom-based criteria have been used [22]. However, it was significantly smaller than the current authors' a priori threshold used to investigate the value of this criterion. Failure of peak flow to be a reliable pointer to exacerbations in COPD contrasts with the experience in asthma [23] and reflects the importance of increases in lung volumes during such episodes rather than changes in forced expiratory flow [24]. Detecting changes of this magnitude is not practical in individual patients and removes the objective reassurance that PEF data provide when identifying asthma exacerbations.

The baseline spirometric severity was not related to the mean symptom change during the episode. Similar absolute changes in symptoms occurred irrespective of the GOLD stage of disease. However, the baseline level of symptoms did differ with GOLD stage, with breathlessness being scored at a higher level in the initial run-in and during the course of an exacerbation in those in the lower GOLD stages. This may explain why such patients are more likely to seek medical attention when they experience an exacerbation.

The questions selected to monitor with the diary card may have limited the ability to detect all changes of note. This diary card was based on the successful model used in studies of asthma [23] and the present data suggest that it may not be ideal for use in patients with COPD. However, symptoms such as breathlessness were reported in just over $60 \%$ of eventbased exacerbations, a figure very similar to that seen in exacerbations reported in one centre in London, UK, where a different type of scoring was adopted [25]. Future studies should address the appropriateness of individual questions in identifying exacerbations and, in particular, whether upper respiratory tract symptoms associated with viral infections [26] occur independently of other single symptom combinations. However, a preliminary report in another large study cohort where questions regarding cough and sputum were included may not suggest a better degree of resolution than presented in the current study [27].

Although, several different objective schemes were devised in this study for relating exacerbations identified by a change in therapy to the daily symptom record, the level of agreement was poor. The choice of a graded diary card suggesting specific thresholds to be exceeded may have contributed to this. The approach adopted to identify exacerbations in the on-going COPD cohort studies was reported by the East London group. This requires the patient to note a worsening of the symptom on at least 2 consecutive days, but does not specify by how much symptoms should deteriorate. There is no standardised diary card available at present for use in COPD, although exacerbations can be identified in groups of patients using a simplified breathlessness, cough and sputum score [28]. More work to validate these instruments is clearly needed. Better dating of diary entries using electronic diary cards should reduce some of the noise in the data. However, more information is need about why patients attend their physicians to receive medication and what the doctor is identifying when treatment is initiated. The present data confirm that these processes are not captured simply by an increasing intensity of pre-specified symptoms.

The current data have a number of practical implications. The difficulty in identifying symptoms or PEF change on the diary card makes the introduction of individual self-management plans in COPD difficult, and may explain the limited success of current approaches to this [29]. Although individually limited, the pooled data around the exacerbation indicates that the prodrome may last a little longer than previously suggested [22], with some patients failing to return to baseline symptoms within the 4 -week window. The average change in total symptom score was not influenced by the therapy prescribed, suggesting that medication does not change the nature of an event where treatment is sought from the doctor, but does change the number of occasions when this happens.

In conclusion, whether particular aetiologies are more relevant to specific symptom patterns cannot be addressed in trial data such as these. However, the close agreement between the maximal group mean change in symptoms and the onset of therapy does support the use of event-based criteria as a simple reflection of the presence of a clinically important event on average in a chronic obstructive pulmonary disease population. The relationship between initial symptoms and the likelihood of future exacerbation may also help in defining those chronic obstructive pulmonary disease patients where exacerbation prophylaxis is most likely to be helpful.

\section{REFERENCES}

1 Murray CJ, Lopez AD. Alternative projections of mortality and disability by cause 1990-2020: Global Burden of Disease Study. Lancet 1997; 349: 1498-1504. 
2 Donaldson GC, Seemungal TA, Bhowmik A, Wedzicha JA. Relationship between exacerbation frequency and lung function decline in chronic obstructive pulmonary disease. Thorax 2002; 57: 847-852.

3 Kanner RE, Anthonisen NR, Connett JE. Lower respiratory illnesses promote $\mathrm{FEV}(1)$ decline in current smokers but not ex-smokers with mild chronic obstructive pulmonary disease: results from the lung health study. Am J Respir Crit Care Med 2001; 164: 358-364.

4 McCrory DC, Brown C, Gelfand SE, Bach PB. Management of acute exacerbations of COPD: a summary and appraisal of published evidence. Chest 2001; 119: 1190-1209.

5 Connors AF Jr, Dawson NV, Thomas C, et al. Outcomes following acute exacerbation of severe chronic obstructive lung disease. The SUPPORT investigators (Study to Understand Prognoses and Preferences for Outcomes and Risks of Treatments). Am J Respir Crit Care Med 1996; 154: 959-967.

6 Mushlin AI, Black ER, Connolly CA, Buonaccorso KM, Eberly SW. The necessary length of hospital stay for chronic pulmonary disease. JAMA 1991; 266: 80-83.

7 Seneff MG, Wagner DP, Wagner RP, Zimmerman JE, Knaus WA. Hospital and 1-year survival of patients admitted to intensive care units with acute exacerbation of chronic obstructive pulmonary disease. JAMA 1995; 274: 1852-1857.

8 Pauwels RA, Calverley P, Buist AS, et al. COPD exacerbations: the importance of a standard definition. Respir Med 2004; 98: 99-107.

9 Anthonisen NR, Manfreda J, Warren CP, Hershfield ES, Harding GK, Nelson NA. Antibiotic therapy in exacerbations of chronic obstructive pulmonary disease. Ann Intern Med 1987; 106: 196-204.

10 Pauwels RA, Buist AS, Calverley PM, Jenkins CP, Hurd SS. Global strategy for the diagnosis, management, and prevention of chronic obstructive pulmonary disease. NHLBI/WHO Global Initiative for Chronic Obstructive Lung Disease (GOLD) Workshop summary. Am J Respir Crit Care Med 2001; 163: 1256-1276.

11 Mahler DA, Donohue JF, Barbee RA, et al. Efficacy of salmeterol xinafoate in the treatment of COPD. Chest 1999; 115: 957-965.

12 Vestbo J, Sorensen T, Lange P, Brix A, Torre P, Viskum K. Long-term effect of inhaled budesonide in mild and moderate chronic obstructive pulmonary disease: a randomised controlled trial. Lancet 1999; 353: 1819-1823.

13 Woolhouse IS, Hill SL, Stockley RA. Symptom resolution assessed using a patient directed diary card during treatment of acute exacerbations of chronic bronchitis. Thorax 2001; 56: 947-953.

14 Vincken W, van Noord JA, Greefhorst AP, et al. Improved health outcomes in patients with COPD during $1 \mathrm{yr}^{\prime} \mathrm{s}$ treatment with tiotropium. Eur Respir J 2002; 19: 209-216.

15 Niewoehner DE, Erbland ML, Deupree RH, et al. Effect of systemic glucocorticoids on exacerbations of chronic obstructive pulmonary disease. Department of Veterans Affairs Cooperative Study Group. N Engl J Med 1999; 340: 1941-1947.
16 Burge PS, Calverley PM, Jones PW, Spencer S, Anderson JA, Maslen TK. Randomised, double blind, placebo controlled study of fluticasone propionate in patients with moderate to severe chronic obstructive pulmonary disease: the ISOLDE trial. BMJ 2000; 320: 1297-1303.

17 Cazzola M, Di Perna F, D'Amato M, Califano C, Matera MG, D'Amato G. Formoterol turbuhaler for asneeded therapy in patients with mild acute exacerbations of COPD. Respir Med 2001; 95: 917-921.

18 Szafranski W, Cukier A, Ramirez A, et al. Efficacy and safety of budesonide/formoterol in the management of chronic obstructive pulmonary disease. Eur Respir J 2003; 21: 74-81.

19 Calverley P, Pauwels R, Vestbo J, et al. Combined salmeterol and fluticasone in the treatment of chronic obstructive pulmonary disease: a randomised controlled trial. Lancet 2003; 361: 449-456.

20 Pauwels RA, Lofdahl CG, Postma DS, et al. Effect of inhaled formoterol and budesonide on exacerbations of asthma. Formoterol and Corticosteroids Establishing Therapy (FACET) International Study Group. N Engl J Med 1997; 337: 1405-1411.

21 Jones PW, Willits LR, Burge PS, Calverley PM. Disease severity and the effect of fluticasone propionate on chronic obstructive pulmonary disease exacerbations. Eur Respir J 2003; 21: 68-73.

22 Seemungal TA, Donaldson GC, Bhowmik A, Jeffries DJ, Wedzicha JA. Time course and recovery of exacerbations in patients with chronic obstructive pulmonary disease. Am J Respir Crit Care Med 2000; 161: 1608-1613.

23 Tattersfield AE, Postma DS, Barnes PJ, et al. Exacerbations of asthma: a descriptive study of 425 severe exacerbations. The FACET International Study Group. Am J Respir Crit Care Med 1999; 160: 594-599.

24 Gibson GJ. Pulmonary hyperinflation a clinical overview. Eur Respir J 1996; 9: 2640-2649.

25 Seemungal TA, Donaldson GC, Paul EA, Bestall JC, Jeffries DJ, Wedzicha JA. Effect of exacerbation on quality of life in patients with chronic obstructive pulmonary disease. Am J Respir Crit Care Med 1998; 157: 1418-1422.

26 Seemungal T, Harper-Owen R, Bhowmik A, et al. Respiratory viruses, symptoms, and inflammatory markers in acute exacerbations and stable chronic obstructive pulmonary disease. Am J Respir Crit Care Med 2001; 164: 1618-1623.

27 Pauwels RA. Characterisation of exacerbations in the TRISTAN study of samleterol/fluticasone propionate (SCF) combination in moderate to severe COPD. Am J Respir Crit Care Med 2003; 167: A949.

28 Leidy NK, Rennard SI, Schmier J, Jones MK, Goldman M. The breathlessness, cough, and sputum scale: the development of empirically based guidelines for interpretation. Chest 2003; 124: 2182-2191.

29 Watson PB, Town GI, Holbrook N, Dwan C, Toop LJ, Drennan CJ. Evaluation of a self-management plan for chronic obstructive pulmonary disease. Eur Respir J 1997; 10: 1267-1271. 